supply of which is necessary with the design of surface-combustion apparatus at present in use.

An article on "Coal-gas for Motor Vehicles" (Times Engineering Supplement, August 3I) gives some figures indicating the effect of compressing coal-gas on its calorific value. It seems that a suitable pressure would probably not exceed $300 \mathrm{lb}$. per sq. in. If this is too high for use in a house, the gas could be passed through a reducing valve before entering any group of houses.

Briefly, high-pressure gas would be supplied to a group of districts with reducing valves where necessary, just as a high-tension electric supply has transformers placed where required.

(2) As the gas would be supplied in bulk, its composition in any one large district would be uniform, thus facilitating the adjustment of the flameless combusters. In fact, they could be standardised, and sent out ready for use from a central depôt for each large district. The combusters would have to be fool-proof; perhaps by arranging to have adjustments only possible by the use of special tools.

(3) It is obvious that a considerable amount of experimental work is necessary, but the benefits to the community would be so great that it appears worth while starting these experiments as soon as possible. Cheap heating combined with absence of smoke is worth trying for.

(4) It is presumed that the gas would be distributed through weldless steel tubes, so far as possible, above ground for convenience of repair, etc., and along railway tracks where possible.

K. C. BRowning.

3 I Boundary Road, St. John's Wood, N.W.8, September I6.

P.S. (October 7).-A supply of high-pressure gas would be of great value to firms running a service of industrial vehicles, the gas being much cheaper than petrol, and the pressure expediting the filling of the containers.

Prof. Browning's letter raises a number of practical points which deserve attention.

$\mathrm{My}$ former letter was mainly concerned with the conservation of a great national asset. Prof. Browning deals with the matter in the interest of the gas consumer.

(I) It is impossible to estimate the amount of coal and labour which are wasted every day in keeping up thousands of little domestic fires to boil an occasional kettle, or the saving of coal and labour which a supply of cheap gas would bring about, but they would certainly be very great.

I am sorry not to have kept in touch with Prof. Bone's later experiments, but they are undoubtedly on the right lines. The key to successful heating is radiation, and the amount of heat radiated from a surface increases very much faster than the temperature. If, therefore, the principle of surface-combustion can be applied to domestic heaters, there should be a great gain in comfort, even with a lesser consumption of gas.

It is interesting to contrast the enormous strides which have been made of late years in the efficiency of methods of lighting (both gas and electric) with the comparative stagnation in the field of domestic heating. True, the margin of waste in the latter has not been nearly so great as in the case of the former, but there is still plenty of room for economy, and Prof. Bone's experiments seem to point the way.

(2) It will be convenient to deliver the gas from the coalfields at a high residual pressure, and it will be quite feasible to distribute it at high pressure if this should be considered desirable. It is a much simpler matter to confine gas at a pressure of $220 \mathrm{lb}$. than elec-

$$
\text { NO. } 2502 \text {, VOL. IOO] }
$$

tricity at 220 volts, and the pressure of the gas could be utilised to deliver air to the surface-combusters.

(3) A good deal of experimental work will be required to solve the practical problems involved. The enterprise of our great gas companies will doubtless be equal to the occasion.

(4) The question of rights of way will demand very careful consideration. Weldless steel tubes present many advantages, but the question of overground $v$. underground pipe lines can scarcely be settled offhand. ARThur J. Martin.

University Hall, Carlyle Square, Chelsea, S.W.3, September 29.

\section{The Harvest Moon.}

The harvest moon is usually stated to be the full moon nearest in date to the autumnal equinox, and to be distinguished by the peculiarity that for a few successive evenings the retardations of the times of rising are at a minimum.

Now, applying these tests to the full moons of September $\mathrm{I}$ and 30 of the present year, it will be found that they are inconsistent. The retardations at Greenwich, from August 29 to September 4, are, in minutes, $30,22,21,19,21,22$, an average of $22 \frac{1}{2}$ minutes; but, from September 27 to October 3 , are $23,20,20$, $22,25,3 \mathrm{I}$, an average of $23 \frac{1}{2}$ minutes, so that for the full moon of September I the retardation was slightly less than for the full moon of September 30 , although the latter was much nearer the date of the equinox.

Possibly Sir George Greenhill, in his very interesting article (NATURE, September 27, p. 67), overlooked this peculiarity, due, of course, to the fact that the moon was at the first date much nearer the ascending node than at the second date. I may add that the average daily retardation in the time of rising is $50 \frac{1}{2}$ minutes, the average length of a lunar day being $24 \mathrm{~h}$. $50 \frac{1}{2} \mathrm{~m}$. In conclusion, I find that the interval between two successive returns of the moon to the meridian may be, in extreme cases, about twelve minutes less, and about seventeen minutes more, than the average.

$$
\text { C. T. WhitMel. }
$$

Invermay, Hyde Park, Leeds, September 28.

\section{Folk-iore and Local Names of Woodlice.}

AMONST the readers of NATURE there are many, I feel sure, who are interested in the folk-lore and local names of the members of our fauna. May I appeal to such for any information bearing upon the heading of this letter?

Already nearly one hundred local names, such as bibble-bug, chisel-hog, cud-worm, palmer, lockchester, slater, tiggy-hog, etc., have been obtained, and the districts noted in which such are in use. Celtic and Gaelic names are particularly desired.

Walter E. Collinge.

The University, St. Andrews, October 4

\section{The Convolvulus Hawk"moth.}

IN reply to Mr. C. E. Robson's letter in Nature of September 20, I write to say that I have lately become the possessor of two specimens of Sphinx convolvuli. The first one was caught at Deal on September iz; it shows signs of wear, and had probably come over from the Continent. The second I took myself in Queen Elizabeth's Walk, Stoke Newington, London, N., on September 22. It was in perfect condition, and had every appearance of having just hatched out. It was resting on a wall close to some bindweed, and it seems probable that it was bred there.

8 Allerton Road, N.ı6, October 4. 